\title{
Representations of translators and translation in Japanese fiction
}

\author{
Judy Wakabayashi \\ Kent State University
}

This paper examines some 40 Japanese fictional works containing portrayals of translators or translation (here understood as including interpreting). It explores Japanese writers' use of translation as a metafictional device, the extent to which these works (mis)represent reality, whether they are positive or negative depictions, and the insights they provide into how translators and translation are regarded by Japanese authors and, by extension, the Japanese public. Recurring themes are analyzed, such as marginality and identity issues, power and fidelity, author/translator relations, attitudes toward translators, and translation as a profession and business. Of particular interest is the question of how Japanese depictions might differ from those by Anglo-American writers.

\section{Introduction}

Fictional treatments of translation ${ }^{1}$ burgeoned in the West in the second half of the 20th century. Strümper-Krobb (2003: 116) attributes this to growing internationalization, while Thiem (1995: 208-209) points to the internationalization of literature itself, and Pagano (2000: 38; see also Pagano 2002: 81) notes that thematizing translation is a way of expressing new cultural configurations - "a way to describe the movement of displacement that characterizes the in-betweenness of the woman, the translator, and the migrant". This fictional move is regarded as symptomatic of the postcolonial world, where travel, migration and diaspora raise questions of identity and produce new (often hybrid) cultural paradigms. In a book examining how the trope of translation is used by some writers as a metaphor for remaking the world in which ethnic Americans find themselves, Martha Cutter (2005: 16) suggests that translation allows us to "hear a double voice" - that of the source text/culture and that of the target text/culture "as it is modified by interaction with the source text/culture".

Another possible cause for the increase in such fictional representations "is the spread of the feeling that as postmoderns we are epigones": "The translator's secondary position with respect to the primary text makes him or her a personification of belatedness, and translation itself a model for all forms of belated cultural endeavour" (Thiem 1995: 209). Conversely, Strümper-Krobb (2003: 116) cites the mounting recognition in literary theory that translation is in fact more than a secondary activity. Since the 1980s poststructuralist moves to examine fiction as an object of theory have led to similar moves in Translation Studies, as fiction has the potential to 
problematize and deconstruct translation because it is "sensitive to relationships and movements difficult to capture through more orthodox analyses" (Pagano 2002: 97), and because its propensity to "play" with "the given ideologemes of its cultural context" makes it "the best place to trace the ideology of translation" (Beebee 1994: 72). Thiem (1995: 210) perhaps somewhat problematically attributes the translator's rise "as alter ego of the postmodern writer" to two factors - "a new awareness of the textual paradoxes emerging from the phenomenon of self-translation, and the apologia for translation in the writings of Jorge Luis Borges".

Whatever the reasons behind this phenomenon, fictional representations are factual artifacts of and further shape the public perception of translation, so they merit investigation just as much as the construction of translation by academic writers - as do any discrepancies between the two. In terms of national origins, Pagano (2000: 39) suggests "a strong predominance of writers associated with postmodern/postcolonial spaces: [...] spaces of tension between multiple languages, cultures, and histories", while Cutter (2005: 12) argues that representations of translation in AngloAmerican works differ from representations by ethnic American writers. Such observations suggest cultural disparities in portrayals of translation. Given my decades-long interest in Japanese culture and Japanese translation, this prompted me to examine Japanese representations of translation. The observations below draw on implicit contrasts with my unpublished study of about 80 Western representations of translators and translation, although space does not permit a full or explicit comparison.

\section{Pseudo-translations and paratextual visibility}

In some of the approximately 40 Japanese works examined here the writer ${ }^{2}$ simply uses translation as a convenient plot device, with less interest in translation itself. Presenting a work as a translation allows the 'translator' to witness or give voice to the events in question or to play bilingual games. Aoyama \& Wakabayashi (1999: 224) note that some Japanese writers have used the expedition of reading a preceding translation, with the translation being "admired or caricatured" or "used merely as an introduction to the author's own version of the same story" or as "a device to create distance from the source text and the cultural stereotypes surrounding it". ${ }^{3}$

The dual-layer plot in Tsuzuki (2003) intertwines alternate chapters representing an American thriller in 'translation' and a plot involving its Japanese 'translator'. The bogus fly leaf comes complete with a statement about translation rights and publication details of the 'source text' and 'translation'. The chapters where the 'translator' appears allow comment on matters such as the editing and publishing process (88-89), including translator's and author's royalties; the necessary research $(95,168,170)$; and translation speed and deadlines (173). Some theorists today advocate making real-life translators' presence and intervention in the text more apparent through foot- 
notes and prefaces, and these aspects have also attracted fictional attention. Tsuzuki adapts the device of the translator's note, with numerous and lengthy in-text annotations purporting to explain American place names, food, puns, and so on. Sometimes the 'translator' even provides excerpts and an explanation of the 'source text'. The spurious notes allow Tsuzuki to make critical comments about America, note differences between American and British English, and introduce otherwise-unfamiliar foreign expressions. The ruse adds deliberate pedantry and permits comment on things Japanese from an outsider's viewpoint, with the 'misunderstandings' of Japanese culture by the American 'author' giving rise to humor. The overdone nature of the notes parodies translators' notes, and those commenting on descriptions of Japanese culture or language by the foreign 'author' would have a particular impact on Japanese readers. By presenting in katakana (the script used for phonetically transcribing foreign words) Japanese-derived expressions such as 'spring picture' and adding a 'translator's note', Tsuzuki sustains the illusion of reading a translation. Or rather, he makes readers conscious of this artifice. Aoyama and Wakabayashi (1999: 219-220) discuss a series of mock translations by Kobayashi that similarly come "complete with the 'original' titles in English, translator's prefaces, and original and translator's notes. [....] The 'translator's preface', while imitating the style typical of the genre, pronounces the unreliability of the information contained in the "source"".

The multi-layered mystery novel by Furukawa (2001) purports to be a Japanese translation of an English translation of a mid- $19^{\text {th }}$ century text by a European geographer. This anonymous text about $18^{\text {th }}$ century Egypt itself contains further embedded layers, with the rendition of oral folktales in written form playing a part in the framing plot - a plot that in turn raises questions of the uniqueness and (ir)reproducibility of an Arabic text translated within this framing story. The translationese-like style adds translational 'authenticity'. Again often unusually lengthy, the over 200 in-text 'translator's notes' comment on a variety of matters - e.g. errors in the source text $(21,183,398)$ or the English translation on which the Japanese translation is based (52); gimmicks in the English translation and omissions by Furukawa, the 'translator' (116); additions by the English translator (285); changes to the visual layout of a poem (157) or the typeface (215); and the inferred date of the intermediate translation (244). In his afterword - itself part of the overall deception - Furukawa relates the provenance of the source text and its English translation and how translators into various languages (including himself) have felt at liberty to change the content on the pretext that the oral transmission of folktales entails transformation. Furukawa 'claims' he decided to translate this as a break from writing novels himself.

Although not a pseudo-translation, in Ogawa (1996) there are clear metafictional parallels between the plot and that of a Russian novel the main male character is translating. The protagonist in Ogawa's novel shares the name Mari with the heroine of the Russian novel and she reminds the translator of the heroine (37); their first kiss takes place immediately after the 
translator tells her about the Russian heroine being kissed by her horseriding instructor (75); Mari has a masochistic desire to be dragged by her hair and drowned by the translator, just as the heroine was abused and drowned by her husband (189); and after the translator discovers that Mari had sex with his nephew he whips her, bringing to mind the whip held by the instructor as he embraced the other Mari (229).

\section{Language learning, relationship to language, and professional motivation}

The corpus contains very few references to how the fictional translators and interpreters (T/Is) gained the linguistic skills essential to their profession. In Miyakoshi (1993), set in northern Japan in the 1850s, fifteen-year-old Denzō learns the Ainu language from two Ainu he worked with as a cook and by following his interpreter brother and father around (44) and using drawings to help him communicate (71). This novel also highlights how bilingual dictionaries have not always been readily available, with the brothers compiling and adding to Japanese-Ainu dictionaries.

Although not a common feature in this corpus, the problematic relationship some T/Is have with their mother tongue is thematized in Tawada (2002):

I'm not well suited to the task of interpreting to begin with. I hate talking more than anything, especially speaking my mother tongue. (16) ${ }^{4}$

I hadn't spoken Japanese in a long time. In the word okaasan (mother) I met my old self, and when I said watashi (I) I felt as though I were my own simultaneous interpreter. (42)

Some fictive T/Is take up this occupation by chance or default. For some (e.g. in Ogawa 1996), the translator's solitary lifestyle offers peace or a means of escape and avoiding worldly concerns, while others are attracted by the freedom this profession offers. In Yoshimoto (1994: 9) an interpreter "decided to do translations at home so she could be there for us kids" after her divorce. The protagonist in Matsuura (2004) is translating the biography of an $18^{\text {th }}$-century British politician in the hope that someday someone might read this work to which he has devoted several years of his life; he finds translation tiring but generally satisfying, even if the book is never published (13). Apart from other motives, translation is a means of making a living, albeit not always a robust one. After the protagonist in Kōno (1997: 318) quit as an opera singer "she'd been thrown back on her [Italian] language skills to survive. She had earned extra money by translating articles for fashion magazines".

It is striking just how rarely T/Is are portrayed as taking up the profession out of a desire to act as cross-linguistic/cultural mediator. On the whole, the notion of the T/I as altruistic linguistic/cultural mediator - a com- 
mon theoretical representation and how T/Is would assumedly like to view their role - seems of little direct interest to fiction writers, Japanese or nonJapanese. One of the few clear cases in this corpus is in Miyakoshi (1993) where, after becoming aware of discrimination against the indigenous Ainu, Denzō decides to become an interpreter so as to help them. Sometimes T/Is are called on or volunteer to become more overt players in the communication process, an act that arguably violates the professional role of a relayer of messages. An example of well-meant intervention is when, after a Japanese man at a lunch for his firm's German clients says "So the women here [in Germany] wear sexy clothing even to work", the interpreter deflects this as "He is admiring that old china and says it is indeed very fine" (Tawada 2002: 14).

The flip side of wanting to become a $\mathrm{T} / \mathrm{I}$ is no longer wishing to work in this field. The narrator in Tawada (2002), a reluctant interpreter whose tongue is stolen, ends up abandoning her profession of speaking on behalf and between. Although it is difficult to explain this surreal fantasy in rational terms, Tawada (herself a translator) is clearly using the tongue and the profession of interpreter in symbolic reference to the issues of identity and communication that face those living in a foreign language and culture.

\section{Marginality and identity}

One feature distinguishing this corpus from many English-language representations is the general absence of T/Is of mixed parentage or non-mainstream ethnicity. Assumedly a reflection of the relative homogeneity of Japanese society, this means the corpus delves little into issues of linguistic and cultural identity. One exception is Yōko Tawada, who now lives in Germany and publishes in both German and Japanese, which has made her very aware of these issues. Evocative of the controversial Sapir-Whorf hypothesis, the introductory Translator's Note to Tawada (2002: vii) asks "If the languages we speak help define us, what happens to the identity of persons displaced between cultures? 'The interesting,' [Tawada] once said in an interview, 'lies in the in-between'."

At times an implicit parallel is drawn between marginality as a T/I and social or psychological (rather than ethnic) marginality, although it is not clear whether writers regard the profession as attracting or producing outsiders. The weak sense of identity on the part of the interpreter in Tawada (2002: 11) is symbolized by how her image fails to materialize in photos. A protagonist in Ogawa (1996) is not named throughout, always being referred to as 'the translator' or 'he', thereby heightening the tension. When posting off his translations he feels a sense of dread, as if he alone is not allowed to die but is condemned to wander forever on the edges of the world, with nobody noticing his absence except perhaps his client seeking to pay him (101-102). He confirms his existence by immersing himself in desire for prostitutes (103). Less marginal are the protagonists in Murakami's novels, 
who "usually impress us, partly due to their half-involvement in society. They are not completely estranged from social life. [...] They never dirty themselves, but instead survive in a rather comfortable world of translation and essay-writing." (Kuroko 1999: 2). Elsewhere translators are often portrayed as timid creatures, perhaps living vicariously through their translations:

You're the type who'd never ... choose any work that might involve constant risks. You leave those jobs to other people. Then, when they've survived the dangers ... and written a book about their experiences, you step in and translate it. (Ōe 1974: 248)

This translator does, however, also represent a rare portrayal of a translator with relatively high status (perhaps partly due to his work as an academic):

"All of them back home have read the book on gorillas that Mitsu translated," she declared. "They say they feel a lot happier now they know I'm under the same roof as such a distinguished scholar. Mitsu's a real member of the establishment, isn't he? (99)

This less-than-intrepid translator eventually does take up the challenge of working as an interpreter in Africa. The image of translation/interpreting as a romantic or cosmopolitan calling is, however, the exception in this corpus. Von Bardeleben (1997: 343) has noted the T/I's "mobility and the potential freedom from nationally defined identities", and in several works the T/I profession functions mainly to allow characters mobility not possible with a 'proper' job, but Japanese works do not highlight the second feature noted by von Bardeleben.

Cutter (2005: 25) observes that in her corpus it is often women who are portrayed as linguistic/cultural mediator. This is possibly in line with the perception of both women and translators as fulfilling a subservient role. The present corpus, however, features more male T/Is, perhaps reflecting the prominent role played by translation in Japanese history, which makes it a more 'suitable' calling for men. Although the link between gender and translation does not feature here, in Yagawa (1998: 474) a woman appends a pseudo-translation commentary to her handmade book of paintings purportedly by a man, 'translating' herself into a different gender from a different time and place (475) in an attempt to bestow the benefits of androgyny on her creative world. ${ }^{5}$

\section{Ethical issues, power and fidelity}

Ethical issues receive less attention in this corpus than in English-language treatments. Professional (mis)conduct is touched on in Kaiko (1965: 60), where the protagonist, tired of translating pen-friend letters, simply invents English, French and German boilerplate answers, later receiving replies from children in Europe correcting his mistakes. When translating their letters for 
Japanese, he omits these parts. The question of competence appears in Natsume (1972), where Terao asks Daisuke for help with places he does not understand. Daisuke responds "Just go ahead and fudge it - what difference does it make? They're paying you by the page anyway, right?", to which Terao replies: “Look, even I can't be that irresponsible. It'll mean a lot of trouble if people point out mistranslations" (134). Despite this display of professionalism, when asked by Daisuke what he will do about the unresolved questions, Terao replies

"Oh, I'll do something - no matter who I ask, there's probably no one who would understand it completely. And anyway, there's no time, so it can't be helped." Terao took it for granted that his livelihood was a far more important concern than any mistranslation.

One strong theme in many Anglo-American representations is the (ab)use of power deriving from the privileged intermediary position of T/Is. Their 'belated' position gives them the final say in the target culture, as Thiem (1995: 213) points out, and their supposedly neutral position can be exploited for personal or altruistic ends. The Japanese corpus, however, reveals little interest in the potentially subversive role of T/Is. Nevertheless, the perception of potential power sometimes gives rise to suspicion or antagonism on the part of those forced to rely on their services:

Interpreters are like prostitutes that serve the occupying forces; their own countrymen hold them in contempt. It's as if the German entering my ears were something like spermatic fluid. (Tawada 2002: 14-15)

The power and freedom accruing to T/Is working in prisoner-of-war camps is touched on in Murakami (1997: 541-2) and Ōoka (1996), a memoir regarded as fiction in the Japanese context, while the interpreter's position between colonizer and colonized is brought out in Miyakoshi (1993).

The long-debated issue of fidelity in translation occasionally surfaces in fictional works:

"You're weak, not really weak, but too kind. You think that you have to be faithful to the structure of the original sentences."

That had been bothering me about my own translations lately, and I thought of quitting.

"That sort of thing is inevitable no matter how hard you try to separate yourself from the text. You're so sensitive, Kazami, that it's going to wear you out." $[\ldots . .$.

"Once you get too involved with a text, it's difficult to let go of it or create it in another language." (Yoshimoto 1994: 117)

Western fictional representations seem particularly interested in the lack of fidelity on the part of T/Is, but this did not emerge as a strong theme in the Japanese corpus. 


\section{Author/translator relationships, and attitudes toward the work of T/Is}

The perception of the translator as mere author-channeller is perhaps that most widely held by the public, but the "indefiniteness of the boundary between authorship and translation, between primary and secondary creation" (Thiem 1995: 215) has led to portrayals of the translator as rival to or traitor of the author, a topic regarded as making for more interesting fiction than the conduit role. This rivalry recurs in many Anglo-American works, but the Japanese writers here express less interest in this. In Tawada (1993) a minor character who gave up translating literature because of the poor income and instead started writing novels, no longer wants her name shown as translator and now seems to despise translating. When the protagonist is advised by this character to write her own novels, on the grounds that translators are not artists, she retorts that she wants to translate and is not doing it simply because she could not make the grade as novelist (68). Later she says she does not want to be in the spotlight like a solo performer, preferring to hide behind the author and finish the translation before anyone notices her (89). In Yagawa (1998: 510-511) the fictional author who invented the protagonist F. G. suddenly appears one night and says it is time for F. G. to 'disappear' because the fictional author wants to bring the novel to an end. Initially averse to the idea, F. G. later asks a male critic to 'silence' her, which he does by placing his penis in her mouth, bringing this pseudotranslator's life to a symbolically significant end (570).

Representations of translators as fulfilling a lowly role tend to prevail. When asked if she is a tourist or prostitute, the protagonist in Tawada (1993: 103) answers that she is neither, but a translator, only to be told it's much the same thing. Yet T/Is can hardly blame others for not respecting their work when they themselves - at least their fictional avatars - show little regard for their achievements. The translator in Ogawa (1996: 22) describes his work as just sitting at his desk all day, looking up words in a dictionary, while the translator in Matsuura (2004: 25) describes both translating and writing as good-for-nothing occupations. The translator below also does not hold his work in much esteem:

I gradually became one with dictionary, Penguin book, and pencil, and all my other selves evaporated, leaving only the one pressing ahead with the translation. It occurred to me vaguely as I went on with my task that if things always went like this I might even last till I died of old age, never experiencing the hardships of labor, never doing work of any particular importance. (Ōe 1974: 127)

\section{Text selection and reception}

Compared with Western representations, the Japanese corpus seems to focus more on the translation of humdrum texts than works of literary merit - perhaps in line with a perception of translation as a quotidian task, perhaps 
reflecting the reality of professional translation, or perhaps because commercial work provides a living that enables fictional translators to engage in other pursuits (although some of these factors presumably apply in nonJapanese contexts too). The translator in Ogawa (1996: 38) says he is not a 'proper' translator asked to translate books, just corporate pamphlets, magazine columns, package inserts, user manuals, business letters and recipes. Such mundane portrayals (e.g. Horie 2001: 58) are parodied by Natsume (1972: 105-7). Only occasionally is more noteworthy content mentioned:

he quit the university and thereafter spent his time leisurely translating curious old texts and the like. Fallen angels and debauched priests, diabolists, vampires, tracts on sordid and sundry topics. (Murakami 1980: 7)

After an amusing grab-gab of translations and their deadlines, a character in Murakami (1980: 32) highlights the seemingly arbitrary nature of the texts that clients choose to have translated:

The real shame was that the clients' names were never written anywhere. I could scarcely imagine who, for any reason, would want to get these things translated (and as RUSH jobs, no less). Perhaps some bear had stopped in its tracks before a stream in expectation of my translation. Or maybe a nurse was waiting wordlessly in her vigil over a terminally ill patient.

The fate of translations after leaving the translator's hands is of only minor interest (e.g. a book review praising a translation in Ōe 1974: 247). In Tawada (1993) a reviewer says a translation smacks of translationese and fails to convey the original's flavor (31) and another reviewer blames everything he disliked about the book on the translator, not the author (32). Afraid of how the novel she is now translating will be received, the translator says she does not identify with any of the characters and stresses that her role is that of translator (69).

\section{The nature of translation}

The corpus gives some idea of how the act of translating is perceived by Japanese authors. One translator in Tawada (1993) says the secret is to read a sentence slowly while inhaling, hold one's breath and translate mentally, then carefully exhale; but reading a single word makes the protagonist-translator short of breath and distracted. Believing fidelity to the unfamiliar feel of each word might be more important (30), she has no leeway to think about the text as a whole and nor does she much care about it. She thinks it might be no bad thing to forget the 'whole' and work this way, but then wonders if perhaps translation is not quite a different operation, perhaps one of metamorphosis - words and the story metamorphose, looking as if they had been like that from the start. In the same work, Japanese words presented in German word-order result in an incomprehensible jigsaw puzzle in places. In 
his afterword to this novel (146) the critic Jinno claims that these passages constitute the faithful, ideal translation advocated by Walter Benjamin, adding (149) that the literality advocated by Benjamin might not be achievable in actual translations, but it is in a novel.

Mention of translation as a decoding-encoding process is quite frequent, with translation often being described (e.g. Kaikō 1965: 60; Horie 2001: 49) as merely converting horizontally written European texts into vertically written Japanese (or vice versa) or as a simple, mechanical operation:

One of the great points about our level of translation was that there was no extra thinking involved. You'd have a coin in your left hand, slap your right hand down on your left, slide away your left hand, and the coin would remain on your right palm.

That's about all there was to it. (Murakami 1980: 13)

Such portrayals are sometimes intended to highlight the invalidity of such views, rather than express the author's own beliefs.

At times translating and interpreting are shown as stressful and fatiguing:

I had to chew the garbage, swallow it, and spit it back out in different words. [....] Everyone began to talk, using my mouth. Their words bolted into my stomach and then back out again, footsteps resounding up to my brain. (Tawada 2002: 17)

Translating exhausts you in a special way. [....] Even with the type of translation work I do now, I sometimes need a total escape, in a place without a story. (Yoshimoto 1994: 117)

The power of translation is sometimes depicted as working negatively, with all three translators of an English book by a Japanese author committing suicide in Yoshimoto (1994). The protagonist says "it probably has to do with the process of putting his English into Japanese. [....] Everyone who is attracted to this book, everyone who wants to translate it, they all have a death wish" (23). The author's son comments that "[i]t wasn't until I started living here that I understood that my father was indeed Japanese and that, even when he wrote in English, Japanese was his true foundation. That's why such disastrous things happen when someone tries to translate his English into Japanese" (24-25). The act of translation can also, however, be therapeutic. The 'I' in Ōe (1996: 53) sends a grieving mother his translation of a letter of condolence by Scott Fitzgerald: "as I put the words into Japanese, I felt somehow that I was writing my own letter to her" (66).

Linguistic issues generally receive little attention, apart from occasional discussions of word choice (e.g. Tawada 1993: 18, 63). There are passing references to the need to research specialized topics; for instance, the translator in Horie (2001: 126) goes to a library to check some unresolved questions and the translator in Kōno (1997: 318) seeks help with terminolo- 
gy from engineers. More often, the need for research and specialized knowledge receives no recognition.

Diachronic translation is mentioned in Tsuzuki (2003: 145-146) when a woman translates Edo-period Japanese into medieval-sounding English (represented here in Japanese) and another character comments that rendering archaic language into archaic language is necessary to be faithful. Diachronic translation is at the core of Enchi (1982), where "the borderlines between fiction and reality, production and reproduction, author and character, translator and critic, male and female, become perforated" (Bargen 1996: 170). In Inoue (1981) a dialect is established by farmers in the rural north as the 'national' language of their town when it secedes from Japan, and this fictitious dialect (which resembles the Tohoku dialect of northern Japan) is used to great humorous effect and also to translate modern Japanese classics, presenting the dialect in a new light to readers of this novel by elevating it to the status of a 'standard' language that acts as the target language here.

\section{Translation as a profession and business}

Fictional portrayals of translators' working methods are dated, with wordprocessing rating scarcely a mention even in recent novels despite its practical importance to translators today. The not atypical work setup of the translator in Ogawa (1996: 74) consists of five sharp pencils, two dictionaries, a paperweight, magnifying glass, paper knife, notebook and the source text. He writes his translations out neatly by hand and with no corrections at all. The very practical issues of speed and deadlines do receive occasional mention (e.g. Ekuni 2003: 7, 125; Miyakoshi 1993: 128), although not always in realistic terms.

There are sporadic indicators of the financial viability of the profession. Miyakoshi (1993: 40) notes that the work of Japanese-Ainu interpreters in the 1850s could be quite profitable, while Mori (1972: 144) suggests that around 1885 a translator could earn "about three yen per page by translating articles on law" - sufficient to pay for an evening's "silly chatter" with a geisha. Translation skills, rare at the time, were clearly more highly valued in Edo and Meiji Japan than today. Even so, in Ōe (1974: 35-6) a book translation on animal trapping "had gone into several editions, and the royalties guaranteed a basic livelihood for my wife and myself". Commercial aspects receive considerable attention in Murakami (1980: 12):

A friend of mine and I leased a condominium ... and opened a small translation service. My friend's father put up the funds, which is not to say that it took any astounding sum of money - just the deposit on the place, and the money for three steel desks, some ten dictionaries, a telephone, and a halfdozen bottles of bourbon. [....]

After a few months, we felt we'd struck a real gold mine. An amazing amount of business found its way to our humble office. [....] 
Everything had a tag-affixed deadline - such and such a date - and was stacked on the left until, in due course, it was transferred to the right. [....]

"No matter who wrote it," boasted the catchphrase on our three-color offset brochure, "there's nothing we can't make intelligible."

Similarly, the protagonist in Murakami (1994: 47) sets up a translation service with a friend after graduation and they scrounge up work by passing out handbills. They also handle advertising, with the protagonist observing that "[d]ull translation jobs or fraudulent copy, it's basically the same. Sure we're tossing out fluff, but tell me, where does anyone deal in words with substance?" (49).

Ōe (1996: 53) and Murakami (1980) mention 'ghost' translating, where an 'understudy' prepares a draft and someone with 'name value' rewrites it, often with little reference to the original. This practice, common in Japan, has not attracted the attention of Western writers, reflecting different professional realities:

I ended up with daily requests from a lot of different people for assistance on translations. They all wanted me to prepare a preliminary translation, on the sly, for the preliminary translation that they were working on for a professor. (Yoshimoto 1994: 43)

The translator in Horie (2001: 143) is uncomfortable when asked to use someone's draft or to work in a team. Collaboration even beyond the grave is mentioned in Ōe (1974: 176):

... the translation, my inner dialogue with the friend who had killed himself. Each time I groped for a word, I would ask myself what he would have used at that point, and enjoy the momentary sensation of communion with the dead.

\section{Conclusion}

This corpus partially mirrors fictional representations in non-Japanese works I have studied, but generally explores the issues in less depth, with some aspects (e.g. metaphors of translating and interpreting ${ }^{6}$ ) receiving little attention. We can only speculate as to whether any 'mirroring' that does exist is a reflection of Western portrayals or an independent representation suggesting deep-seated cross-cultural perceptions or realities of translation. Japanese writers have paid less attention to interpreters than translators, perhaps reflecting market needs and realities in modern Japanese history, although the portrayals often simplify or distort the issues. Strümper-Krobb (2003: 121) attributes the gap between fiction and reality to "differences in agenda and discourse", but ignorance of the T/I profession on the part of writers is clearly another factor. The overall picture emerging from the Japanese corpus is somewhat negative, rather than a view of the T/I as "transformer, re- 
creator, performer, even liberator of the original text" (Appel 2002: 1); nor does it tally with Appel's claim in relation to certain Western works that the theme they share is the idea of translation as "the product of a dialogue [...] between the author and the translator". References to translation in Japanese works are often minor and incidental, except perhaps in how they contribute to characterization as something of a dilettante. Aoyama (2003) suggests that typical images of translation in Japanese fictional works include "as a sign of advanced literacy and knowledge of hegemonic culture, and ... as a fashionable job for a young woman".

Given translation's vital role in modern Japanese history, the relative dearth of fictional comment seems surprising, but can perhaps be partly attributed to the fact that translation in Japan has historically involved little direct contact with foreigners. The process of taking in foreign texts has typically not required Japanese individuals to grapple with issues of cultural or self-translation in a setting of direct and personal contact with the foreign. I would argue that even today Japanese writers - with notable exceptions such as Ōe, Murakami, Tawada and Mizumura (author of Japan's first 'bilingual novel', published in 1995 and tellingly entitled Shi-shōsetsu: from left to right) - are still of a largely insular mindset. The novelist/translator Natsuki Ikezawa (qtd. in Sakakibara 2004: 15) believes more diaspora writers (e.g. ethnic Korean writers) will emerge in Japan, but only on the periphery of the literary landscape. Yonaha (qtd. in Kobayashi 2004: 35) suggests that two of the six main themes addressed by contemporary Japanese women writers are "the borderlessness of language, ethnicity, and gender" and "self-searching journeys characterized by cross-cultural experiences and a traveler's point of view" - themes that lend themselves to fictional representations of translation, so perhaps we will witness more such works in Japan in the future.

\section{Bibliography}

\section{Primary sources}

Ekuni, Kaori (2003). Twinkle, Twinkle (tr. E. Shimokawa). New York: Vertical.

Enchi, Fumiko (1982). "Love in Two Lives - The Remnant". Kyoko Selden \& Noriko Lippit (eds). Japanese Women Writers. New York: M.E. Sharpe, 97-111.

Furukawa, Hideo (2001). Arabia no yoru no shuzoku. Tokyo: Kadokawa Shoten.

Futabatei, Shimei (1967). Ukigumo. Japan's First Modern Novel: Ukigumo of Futabatei Shimei (tr. Marleigh Grayer Ryan). New York:, Columbia UP.

Hasumi, Keiichi (2001). Suiyō no asa, gozen sanji. Tokyo: Shinchōsha.

Hayashi, Mariko (1991). "Wine" (tr. D. Lawson). Mitsios (1991), 138-151.

Horie, Toshiyuki (2001). Itsuka Ōji eki de. Tokyo: Shinchōsha.

Inoue, Hisashi (1981). Kirikirijin. Tokyo: Shinchōsha.

Kaikō, Takeshi (1965). "Mita". Mita, yureta, warawareta. Tokyo: Chikuma Shobō, 55-93. 
Kawabata, Yasunari (1956). Snow Country (tr. E. Seidensticker). Harmondsworth: Penguin Books.

Kobayashi, Nobuhiko (1984). Hatsugo kunren. Tokyo: Shinchōsha.

Kobayashi, Nobuhiko (1988). Chihaya fuyu okuno hosomichi. Tokyo: Shinchō Bunko.

Kōno, Taeko (1997). "Toddler-Hunting” (tr. L. North). T. W. Goossen (ed.). The Oxford Book of Japanese Short Stories. Oxford: Oxford UP, 313-333.

Matsuura, Hisaki (2004). Hantō. Tokyo: Bungei Shunjū.

Mitsios, Helen (ed.) (1991). New Japanese Voices: The Best Contemporary Fiction from Japan. New York: The Atlantic Monthly Press.

Miyakoshi, Kyōhei (1993). Shōsetsu: Gempyō no misaki: Ainu-go tsūji, Akitaya Denzō. Akita: Mumyōsha Shuppan.

Mizumura, Minae (1995). Shi-shōsetsu: from left to right. Tokyo: Shinchōsha.

Mori, Ōgai (1972). Vita Sexualis (tr. K. Ninomiya \& S. Goldstein). Rutland/Vermont/ Tokyo: Charles E. Tuttle.

Murakami, Haruki (1980). Pinball, 1973 (tr. A. Birnbaum). On line at: http://64.233.187.104/search?q=cache:dkTXVh91-PAJ:users.sdsc.edu/ kericson/murakami/pinball1973.pdf+\%22Pinball,+1973\%22\&hl=en (consulted 08.07.2005).

Murakami, Haruki (1990). Wild Sheep Chase (tr. A. Birnbaum). New York: Penguin Books.

Murakami, Haruki (1994). Dance Dance Dance (tr. A. Birnbaum). Tokyo: Kodansha International.

Murakami, Haruki (1997). The Wind-Up Bird Chronicle (tr. J. Rubin). Tokyo: Shinchōsha.

Murakami, Haruki (2000). "Hachimitsu pai". Kami no kodomo wa mina odoru. Tokyo: Shinchōsha, 183-237.

Murakami, Haruki (2001). Sputnik Sweetheart (tr. P. Gabriel). New York: Vintage International.

Natsume, Sōseki (1972). I am a Cat (tr. A. Itō \& G. Wilson). Tokyo: Charles E. Tuttle Company.

Natsume, Sōseki (1978). And Then (tr. N. Field). Tokyo: University of Tokyo Press.

Ōe, Kenzaburō (1996). An Echo of Heaven (tr. M. Mitsutani). Tokyo/New York: Kodansha International.

Ōe, Kenzaburō (1974). The Silent Cry (tr. J. Bester). Tokyo: Kodansha International. Ogawa, Yokō (1996). Hoteru Airisu. Tokyo: Gakken.

Ōoka, Shōhei (1996). Taken Captive (tr., ed. W. P. Lammers). New York: John Wiley \& Sons.

Shiba, Ryōtarō (1982). Na no hana no oki. Tokyo: Bungei Shunjū.

Shimada, Masahiko (1991). "A Callow Fellow of Jewish Descent" (tr. H. Satō). Mitsios (1991), 1-22.

Shimizu, Yoshinori (1991). Ese monogatari. Tokyo: Kadokawa Bunko.

Shimizu, Yoshinori (1993). Jack and Betty Forever (tr. F. Schodt).Tokyo: Kōdansha.

Tawada, Yōko (1999). Moji ishoku. Tokyo: Kawade Bunko.

Tawada, Yōko (2002). "The Bath" (tr. Y. Selden). Where Europe Begins. New York: New Directions Books.

Tsuzuki, Michio (2003 [1964]). Sanjū roshutsu. Tokyo: Kōbunsha.

Yoshimoto, Banana (1994). N.P. (tr. A. Sherif). New York: Washington Square Press. Yagawa, Sumiko (1998). Ushinawareta niwa. Yagawa Sumiko sakuhin shūsei. Tokyo: Shoshi Yamada, 410-571. 


\section{Secondary sources}

Aoyama, Tomoko (2003). Personal communication (7 May 2003).

Aoyama, Tomoko \& Judy Wakabayashi (1999). "Where Parody meets Translation". Japan Forum 11(2), 217-230.

Appel, Anne Milano (2002). "Extremes of 'Remembering': Translation as 'Figura”". Tradurre 3(1).

Bargen, Doris G. (1996). “Translation and Reproduction in Enchi Fumiko's ‘A Bond for Two Lifetimes-Gleanings'. P.G. Schalow \& Janet A. Walker (eds). The Woman's Hand. Stanford: Stanford UP, 165-204.

Beebee, Thomas (1994). "The Fiction of Translation: Abdelkebir Khatibi's Love in Two Languages". Sub/stance 73, 63-78.

Cutter, Martha J. (2005). Lost and Found in Translation: Contemporary Ethnic American Writing and the Politics of Language Diversity. Chapel Hill: University of North Carolina Press.

Kobayashi, Chikako (2004). "Recent Japanese Writing". SWET Newsletter 106, December 2004, 32-37.

Kuroko, Kazuo. "The Return from the Lost World: Dance Dance Dance". On line at: http://www.netwave.or.jp/ andrew/lostwld.htm (consulted 15.11.1999).

Pagano, Adriana S. (2000). "Sources for Translation Theory: Fiction in Latin America". ATA Chronicle 29(4), 38-44.

Pagano, Adriana S. (2002). "Translation as Testimony: On Official Histories and Subversive Pedagogies in Cortázar". Maria Tymoczko \& Edwin Gentzler (eds). Translation and Power. Amherst/Boston: University of Massachusetts Press, 80-98.

Sakakibara, Tomoki (2004). "Ikezawa Natsuki's World". SWET Newsletter 106, December 2004, 3-15.

Strümper-Krobb, Sabine (2003). "The Translator in Fiction". Language and Intercultural Communication 3(2) [special Issue: Moving Between Worlds: The Transcultured Self in the Sphere of Creative Practice, ed. Alice Tomic \& Evelyne Glaser], 115-121.

Thiem, Jon (1995). "The Translator as Hero in Postmodern Fiction". Translation and Literature 4(2), 207-218.

1 Here 'translation' is understood as encompassing interpreting. The distinction is not always made by the public, including writers, and despite clear differences the two professions share many features.

2 Several of the writers (e.g. Horie, Ekuni, Yagawa, Enchi, Tsuzuki and Murakami) are or have been translators, giving them firsthand understanding of translation. People tend to write about what they know, and writers have long used translation as a way of polishing their writing skills.

3 Their discussion of how parodies highlight and defamiliarize aspects of translation in Japan includes parodies of diachronic and pedagogic translations, translationese, and the idiosyncratic style of simultaneous and consecutive interpreting.

${ }^{4}$ All quotations here are taken from published English translations as cited in the Bibliography.

5 This portrayal takes on extra significance given that Yagawa 'assisted' her former husband, Tatsuhiko Shibusawa, by producing translations that were subsequently edited by him and published under his name, including that of Sade's L'histoire de Juliette, the subject of a famous obscenity case in Japan.

6 The idea of 'pouring' appears in Murakami (1980), and translation is portrayed as 'carrying something across to the other shore' in Tawada (1993: 30). 
